\title{
EFFECT OF SUGAR CANE JUICE ON SLUMP VALUES, SETTING TIMES AND STRENGTH OF CONCRETE
}

\author{
A. W. Otunyo ${ }^{1, *}$, S. C. Onwusiri ${ }^{2}$ and N. Nwaiwu ${ }^{3}$

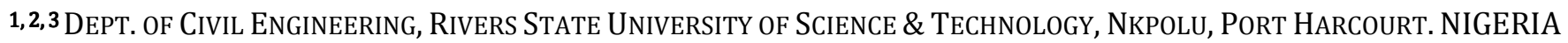 \\ E-mail addresses:1 umutuigili@yahoo.com, 2 kingdavidwealth97@yahoo.com,3n_nwaiwu@yahoo.com
}

\begin{abstract}
The effect of sugar cane juice, (SCJ) on slump values, setting time and compressive strength of concrete cubes was investigated. A total of 32 concrete cubes of size $150 \times 150 \times 150 \mathrm{~mm}$ with a mix ratio of 1:2:4 were cast with different percentages of unfermented sugar cane juice replacing some proportion of water in the concrete mix. Water/Sugar Cane Juice/cement ratio was held constant at 0.45. The concrete cubes were prepared by replacing water with SCJ in the following proportions 0, 25, 50 and 100\%. The cubes were cured, tested and the physical properties of interest in this study were determined. The slump values of the concrete decreased from 40mm at 100: 0 (water:SCJ) to 18mm at 50:50 (water:SCJ) and to 0mm (collapse) at (0:100) (water :SCJ). The final setting time of concrete increased with increase in proportion of SCJ. The highest final setting time of 42 hours (considered excessive), occurred at 75:25 (water:SCJ) proportion. The compressive strength of the (water:SCJ) concrete decreased as the percentage of SCJ increased up to 25\% SCJ. Thereafter, an increase in compressive strength was noticed up till 100\% SCJ, with a maximum strength of $13.08 \mathrm{~N} / \mathrm{mm}^{2}$ occurring at $100 \%$ SCJ at 28 days. The early strength reduction is due to quick-setting of the concrete, at 25\% SCJ, retardation commences and the strength of concrete increases. The study has been carried out at 0, 25, 50 and 100\% replacement by weight of potable water with SCJ. A comparative study has been done between concrete made with potable water and those made with water/sugar cane juice.
\end{abstract}

Keywords: sugar cane juice, slump values, compressive strength, setting time.

\section{INTRODUCTION}

The addition of water to cement in the presence of aggregates, makes the mixture to set and harden gradually under normal climatic conditions to form concrete. This mixture when placed in mould or formwork and allowed to cure becomes hard like stone. The hardening is caused by chemical reaction between the water and cement. The fine and coarse aggregates bond with cement and strengthen after curing.

The strength, durability and other features of this conglomerate material depend on the properties of the mix, its constituents, the method of compaction and other controls during placing, curing etc. All concretes made with lightweight aggregate exhibit a higher moisture movement than is the case with normal weight concrete Neville [1].
In many parts of the world, a combination of high temperatures, low relative humidity and hot wind that blows across the environment result in rapid evaporation of water from fresh concrete surface. As a result, concrete sets earlier, leaving little or no time for concreting operation.

For example, it has been reported that, when the temperature of cement mortar with a water/cement $(\mathrm{w} / \mathrm{c})$ ratio of 0.6 is increased from $27.8^{\circ} \mathrm{C}$ to $45.5^{\circ} \mathrm{C}$, both initial and final setting times are nearly halved [2]. In order to provide proper time for concreting operation, especially when unavoidable delays between mixing and placing occur, and to save concrete from other detrimental effects of adverse climatic conditions, cement set retardation or use of retarding admixtures is necessary [3].

Admixtures are materials other than water, aggregates, hydraulic cement and any other 
reinforcement materials, used as an ingredient of concrete or mortar and added to a batch before or during concrete mixing. A retarding admixture/ retarder is an admixture that retards the setting time of cement concrete, mortar or grout [4].

Bazid and Bulent [3] investigated the effect of pure sugar on setting time of various types of cement. The investigation concluded that setting time of cement was retarded by incorporation of sugar in cement under all conditions of curing. The extension in setting time was increasing with an increase in sugar content up to a certain limit (approximately $0.15 \%$ ) and then started to drop with further increase in sugar content, accelerated the cement-setting when a higher sugar content $(>0.3 \%)$ was used. Relatively low retarding tendency was shown by sugar under the second and third curing condition. $0.15 \%$ sugar-content acted as optimum sugar content for retarding the setting time.

The paper [5] carried out an investigation on retarding action of sugars on cement hydration. It has been proven that sugar interferes, with the cement binding process in the concrete. A theory suggests that when concrete mixture contains sugar, the sugar molecules attach themselves to the hydrating cement and inhibit the chemical reactions involved in stiffening the material.

Another theory, called the "precipitation theory", suggests that the addition of sugar increases the concentration of calcium, aluminium and iron in concrete. The sugar molecules combine with these metals to form insoluble chemical complexes that coat the cement grains. Several key chemical processes that harden the concrete are then impeded. Hydration slows down the process and concrete takes longer to set. For this reason, sugar is known as a retarder. Retarders normally increase the setting time of concrete.

It is important to note that all sugars do not retard cement hydration equally. Lactose, which is the sugar found in milk is a moderate retarder. [6]

In [3] it was observed that a retarding admixture causes cement set retardation by the following mechanisms.

1) Adsorption of the retarding compound on the surface of cement particles, forming a protective skin, which slows down hydrolysis.

2) Adsorption of the retarding compound onto nuclei of calcium hydroxide, poisoning their growth, which is essential for continued hydration of cement after the end of induction period.
3) Formation of complexes with calcium ions in solution, increasing their solubility and discouraging the formation of the nuclei of calcium hydroxide

4) Precipitation around cement particles of insoluble derivatives of the retarding compounds formed by reaction with highly alkaline aqueous solution, forming a protective skin.

Erdogan in [7] reported that retarding admixtures are mainly based on materials having ligsulfonic acids and their salts, hydroxyl-carboxylic acids and their salts, sugar and their derivatives and inorganic salts such as borates, phosphates, zinc and lead salts.

Previous studies used pure processed sugar to determine the effect of sugar on the setting time of various types of cements.

The objective of this study is to investigate the effect of sugar cane juice (SCJ) on concrete properties such as bulk density, setting-time, workability and compressive strength.

This study used sugar cane juice which is obtained from one of the several species of a tall perennial sugar cane from the grasses of the saccharum tribe Andropogoneae, to study the effect of SCJ on the slump values, setting-time and compressive strength of concrete.

\section{METHOD}

The sugar cane used for the study, were obtained from the fruit market in D/Line area of Port Harcourt. The original source of the sugar cane is Northern Nigeria. They were cleaned, peeled, washed and cut into smaller pieces before the juice was extracted by putting the cut pieces into bags. The bags were then subjected to pressure by the use of four iron rods with fixed rebars to compress and extract the sugar cane juice. The extracted SCJ was filtered in order to remove some residual particles of the sugar cane fibre. A total of thirty-two (32) cubes were cast from one mix proportion (1:2:4) but with varying percentages of unfermented sugar cane juice and at water/cement $(\mathrm{w} / \mathrm{c})$ ratio of 0.45 . Water was partially replaced by SCJ in the following proportions: $0 \%, 25 \%, 50 \%$, and $100 \%$. Slump test, setting time and concrete cube compressive test were carried out. The concrete cubes were crushed after $3,7,14$ and 28 days and the various compressive strength values recorded. The Bulk Density of the cement cubes was also determined. 


\subsection{Bulk Density of Cubes:}

The Bulk density of the cement, river sand, gravel and water/sugar cane juice at $\mathrm{w} / \mathrm{c}$ ratio of 0.45 was determined at 3, 7, 14 and 28 days, using [8].

\subsection{Setting Times of Water/SCJ Concrete:}

The setting time of the concrete made with replacement of water by $0.25,50,100 \%$ SJC was obtained using [9].

\subsection{Slump Values of Water/SCJ Concrete}

The slump values of the concrete made with replacement of water by $0,25,50$, and $100 \%$ SJC was obtained using [9].

\subsection{Compressive Strength Test:}

Metal moulds measuring $150 \mathrm{~mm} \times 150 \mathrm{~mm} \times 150 \mathrm{~mm}$ were used to cast the concrete cubes. A total of 32 cubes were prepared for the mix ratios of 1:2:4 and proportions of (water:SCJ), 0:100, 25:75, 50:50, and 100: 0 . The samples were left to cure for $3,7,14$ and 28 days, respectively.

The concrete cubes were loaded to failure using compression machine in the laboratory. The tests were performed in a room with $90 \%$ humidity and room temperature of between $25^{\circ} \mathrm{C}$ and $29^{\circ} \mathrm{C}$.

The weight of each cube of concrete for the compressive strength test was $2.5 \mathrm{~kg}$. All the tests were in accordance with [11], [12], and [13].

\section{RESULTS PRESENTATION AND DISCUSSIONS}

The values of the bulk density increased at all ages as the percentage of the SCJ in the concrete increased. Bulk density is related to strength and [15] have shown that the strength of compressive strength of concrete increases as the percentage of sugar cane bagasse ash increases in concrete.

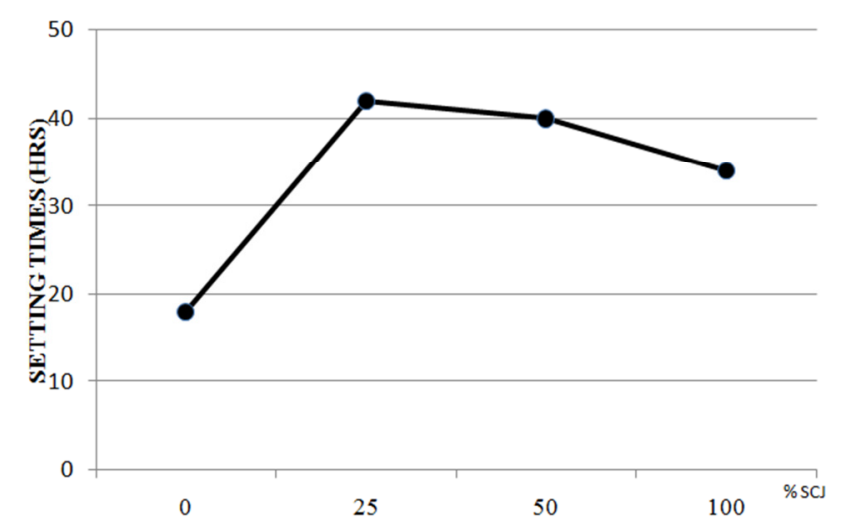

Figure 1: Setting times versus percentage replacement of water with $S C J$
Figure 1 shows a Plot of the setting times versus the various (SCJ:water) replacement proportions. The paper [14] demonstrated that the setting time of concrete increased up to $0.05 \%$ sugar content in concrete.

Figure 2 shows a plot of the slump values for the various replacement proportions of water with SCJ. Slump values of the concrete decreased as the quantity of SCJ increased. Slump values of $40 \mathrm{~mm}$ at $0 \%$ SCJ: $100 \%$ water was obtained. The slump values decreased to $23 \mathrm{~mm}$ at $25 \%$ SCJ: $75 \%$ water, $18 \mathrm{~mm}$ was obtained for the 50: 50 (SCJ/water). The concrete mould collapsed at $100 \%$ SCJ: $0 \%$ Water. It means the addition of SCJ increases the water demand in concrete for achieving a desired workability, which is not good news for high performance concrete.

Fig. 3 shows the plot of the compressive strength of the (SCJ:water) concrete at 3, 7, 14 and 28 days. The compressive strength of the (water:SCJ) concrete decreased as the percentage of SCJ increased up to $25 \%$ SCJ.

Table 1: Physiochemical analysis of the sugar cane juice with NIS 235 [17].

\begin{tabular}{|c|c|c|c|}
\hline S/No & Parameter & Result & Standard \\
\hline 1 & $\mathrm{pH}$ & 5.67 & $>5$ \\
\hline 2 & Specific Gravity & 0.968 & $0.90-0.99$ \\
\hline 3 & Sugar Content (\%) & 15.1 & - \\
\hline 4 & Total Solid (mg/kg) & 67.6 & $<83$ \\
\hline 5 & Water Content (\%) & 20.44 & $<25$ \\
\hline 6 & Sulfure $(\mathrm{mg} / \mathrm{kg})$ & 0.08 & 1.0 \\
\hline 7 & Lead (mg/kg) & 0.04 & 0.3 \\
\hline 8 & Copper (mg/kg) & 0.02 & 0.5 \\
\hline 9 & Acidity (mg/koH/g) & 0.70 & 1.5 \\
\hline 10 & Arsenic Acid (mg/kg) & $<0.01$ & 0.2 \\
\hline 11 & Salinity (ppm) & 0.56 & 1 \\
\hline 12 & Conductivity (us/cm) & 5.06 & - \\
\hline 13 & Iron $(\mathrm{mg} / \mathrm{kg})$ & 2.80 & 5 \\
\hline
\end{tabular}

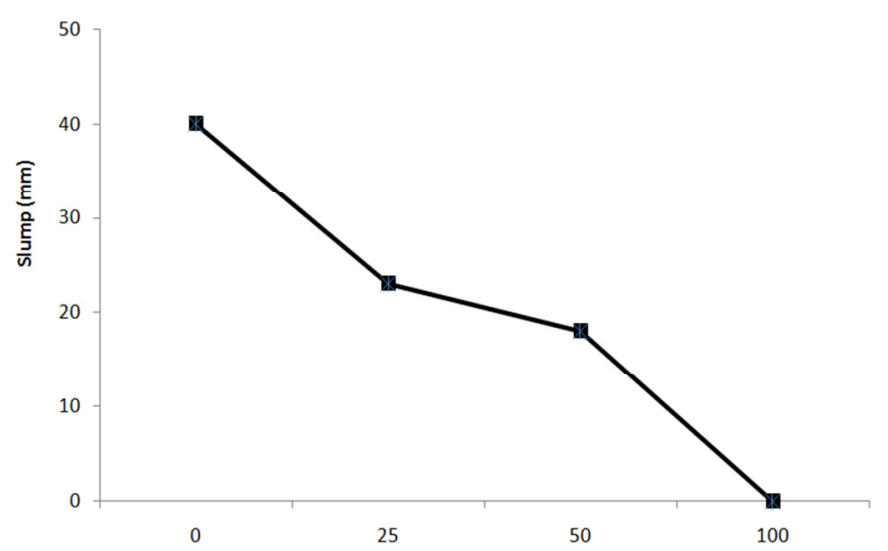

Figure 2: Slump values versus percentage replacement of water with $S C J$

Vol. 34, No. 3, April 2015 


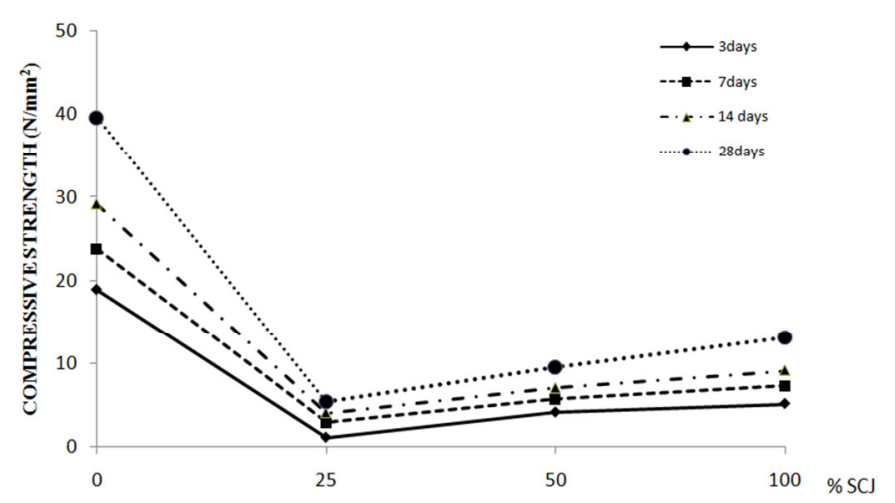

Fig. 3: Compressive strength of (water:SCJ) concrete

Thereafter, an increase in compressive strength was noticed up till $100 \%$ SCJ, with a maximum strength of $13.08 \mathrm{~N} / \mathrm{mm}^{2}$ occurring at $100 \% \mathrm{SCJ}$ at 28 days. Neville [6] observed that sugar when used as a retarder severely reduces early strength of concrete for all ages, thereafter the strength increases at all ages. The early decrease in strength is due to quicksetting. As the quantity of SCJ increases, retardation sets in leading to increase in strength. In this study $25 \%$ SCJ is the optimum replacement for producing higher strength concrete. Asma, et al [15] observed optimum replacement for producing high strength concrete at between $5 \%$ to $15 \%$ of sugar cane bagasse ash. This could be explained from the work of [14] that showed an initial decrease in soundness of cement due to effect of sugar up to $0.06 \%$ sugar and increase in soundness thereafter up to $0.08 \%$. There is a relationship between soundness of cement and strength of concrete produced with such cement. It is believed that retarders modify crystal growth or morphology, becoming absorbed on rapidly formed membrane of hydrated cement and slowing down the growth of calcium hydroxide nuclei thus forming a more efficient barrier to further hydration than is the case without a retarder [16]

Table 1 is the Chemical Analysis of the Sugar Cane Juice. From the physiochemical analysis of the SCJ, its $\mathrm{pH}$ is 5.67 which is acidic. $67.6 \%$ of it, are solids, sugar content is $15.1 \%$ while water content is $20.44 \%$. The decrease in the compressive strength of the concrete cubes with increase in the quantity of SCJ is due to the fact that the components of concrete break down during contact with acid. The compressive strength slightly increases at $25 \%$ SCJ. [6] also stated that sugar interferes with the cement binding process in the concrete because the sugar molecules attach themselves to the hydrating cement and inhibit the chemical reactions involved in stiffening the material.

\section{SUGGESTIONS FOR FURTHER RESEARCH}

(a) It is recommended that further research be carried out with a reduction in the weight or volume of SCJ from 25, 50, and $100 \%$ replacement to about $0.5 \%, 1 \%, 5 \%$ and $10 \%$ in order to experience reduced setting time as against the very long setting times obtained in this study. It is also expected that the compressive strength of the concrete may increase appreciably.

(b) There is also a need to study the effect of water replacement with sugar cane juice on some other physical properties of concrete such as shrinkage and permeability.

\section{CONCLUSION}

Setting time was retarded by the partial replacement of water with sugar cane juice.

Slump values decreased as the quantity of sugar cane juice increased in the mix.

Compressive strength of the concrete decreased from $39.0 \mathrm{~N} / \mathrm{mm}^{2}$ at $0 \% \mathrm{SCJ}: 100 \%$ water to $13.08 \mathrm{~N} / \mathrm{mm}^{2}$ at $100 \%$ SCJ : $0 \%$ Water. This value of compressive strength partially satisfies the strength for lightweight concrete.

\section{REFERENCES}

[1] Neville A. M., and Brooks J. J. (2004), Concrete Technology, Malaysia: Prentice Hall.

[2] Fattui N. I. (1988). The setting of mortar mixes subjected to different temperatures. An International Journal of Cement and Concrete Research, Vol.15, No. 1.

[3] Bazid K. and Bulent B. (2002). The effect of sugar on setting-time of various types of cements. Quarterly Science Vision Vol.8(1) July,-September, 2002.

[4] ASTM Standards for cement and concrete. 1982.

[5] Thomas N. L. and Birchall J. D. (1983). The retarding action of sugars on cement hydration. $A n$ International Journal of Cement and Concrete Research, Vol. 13, No. 6.

[6] http://media.www.thevarsity.ca/media/sto

[7] Erdogan T.Y. (1997). Admixtures for Concrete, Middle East Technical University Ankara-Turkey.

[8] BS 812-2: (1995). Testing of aggregates. Methods for determination of density. British Standards Institute, London. United Kingdom. 
[9] BE EN 196-3: (1995). Methods of testing cement. Determination of setting time and soundness. British Standards Institute, London. United Kingdom.

[10] BS 1881 Part 102: (1983). Method of determination of slump. British Standards Institute, London. United Kingdom.

[11] BS 1881, (1983) Part 114. Methods for determining hardened concrete strength. British Standard Institute, London. United Kingdom.

[12] BS 1881 (1996) Part 108. Method for making test cubes from fresh concrete. British Standards Institute, London. United Kingdom.

[13] BS EN 12390-1(2012). Testing of hardened concrete shapes, dimensions and other requirements for specimens and moulds. British Standards Institute, London. United Kingdom.

[14] Akogu E.A. (2011). Effects of sugar on physical properties of ordinary Portland cement paste and concrete. Assumption University Journal of Technology, Thailand. 14(3); 225-228.

[15] Asma.A.E.H., Nasir S., Muhd F.N. and Fareed A.M. (2014). Compressive strength and microstructure of sugar cane bagasse ash concrete. Research Journal of Applied Sciences, Engineering and Technology, 7(12); 2569-2577.

[16] Neville A.M. 2006 . Properties of concrete. $4^{\text {th }}$ ed., Dorling Kindersley, New Delhi, India.

[17] NIS 235 (1987). Nigerian Industrial Standards. Standards for fruit juices. 